\title{
An empirical approach for delineating fine scaled spatial patterns of freezing rain in the Appalachian region of the USA
}

\author{
Charles E. Konrad II* \\ Department of G eography, University of N orth C arolina at Chapel Hill, C hapel Hill, N orth Carolina 27599-3220, USA
}

\begin{abstract}
A nalyses of freezing rain in the United States are restricted to the use of a sparse network of first-order stations that provide hourly reports of weather type. From this network, spatial analyses of freezing rain are limited to broad scales. Terrain features, however, can strongly modify these patterns at finer spatial scales. This is especially the case immediately east of the Appalachian M ountains, where cold air wedges commonly set up in conjunction with the approach of cyclonic disturbances and precipitation. In this study, an empirical approach is developed whereby daily climatological variables are used to predict mean annual freezing rain attributes over a dense network of cooperative observation stations in the Appalachian region. Since freezing rain occurs when temperatures are at or below the freezing point, it is hypothesized that mean annual frequencies of daily high and low temperatures in a given range near $0^{\circ} \mathrm{C}$ on days in which rain is observed (wet days) provide a surrogate for various annual attributes of freezing rain. In order to test this hypothesis, these mean annual temperature characteristics are correlated with the mean annual number of freezing rain events (NFR) and hours of freezing rain (HFR) from a sample of first-order weather stations that observe freezing rain. Using the strongest identified relationships, regression models are developed to predict HFR and NFR. Over $80 \%$ of the variance in HFR and NFR is explained by the mean annual frequencies of daily minimum temperature less than 0 and $-2^{\circ} \mathrm{C}$, respectively, on wet days. These models are applied to daily climatological (e.g. temperature, precipitation, and snowfall) summaries at selected cooperative observer sites in order to generate estimates of freezing rain occurrence. These estimations provide input for maps that better delineate spatial patterns of freezing rain.
\end{abstract}

KEY WORDS: Freezing rain · Icing $\cdot$ Appalachian

\section{INTRODUCTION}

Although snow and sleet exert a strong influence on economic and human interests, the impacts of ice storms are often much greater. These storms disrupt transportation, increase accident rates, and snap power lines and tree limbs. In some cases, millions of power customers may go without electricity and heat for days. For example, the severe ice storm that affected New England, upstate New York, and southeast Canada in J anuary 1998 resulted in more than 3.5 million utility customers losing power. Overall damages were estimated to be over $\$ 2$ billion (NCDC

*E-mail: cek@email.unc.edu
1998). The February 1994 ice storm across the southeastern U.S. left 2 million utility customers without power and damages totaled more than $\$ 3$ billion (NCDC 1994). The damage to trees due to ice loading has a marked effect on tree growth during the subsequent growing season, at least for various species of pine in the Piedmont region of the southeastern U.S. (Travis \& Meentemeyer 1991). In regions where ice storms are common, such as the Piedmont, the cumulative affects of stunted growth during years with ice storms can markedly reduce the timber harvest.

The occurrence, duration, and spatial extent of freezing rain in a given event are controlled by lower tropospheric thickness and subtle fluctuations of temperature around the freezing point. As the depth of the subfreezing layer is increased, sleet is more likely than 
freezing rain. However, it should be noted that the average surface temperatures associated with sleet are typically higher than those associated with freezing rain, at least over the southeastern U.S. (Gay \& Davis 1993). This is due to the fact that freezing rain is restricted to periods in which temperatures are below freezing, as sleet may be observed when temperatures are several degrees above freezing.

Freezing rain attributes can vary strongly across a rolling or mountainous landscape, where temperature variations correlate with elevation (e.g. Anthes 1976) and slope aspect (i.e. windward and north-facing slopes display lower temperatures). Climatologies of the phenomenon are restricted to the analysis of station records that contain hourly observations of weather type (e.g. freezing rain). In the United States, only a small fraction of the weather stations provide these hourly observations. Therefore, the fine-grained spatial patterns of freezing precipitation that relate to the topography features cannot be identified. In particular, it is unclear how the mean annual characteristics of freezing rain vary across a given terrain, especially where it is complex or mountainous. In this study, daily temperature extremes, precipitation, and snowfall totals from 23 first-order weather sites are used to develop empirical relations between temperature and climatological occurrence of freezing rain. These relationships are then applied to daily weather summaries from a spatially intensive cooperative network in order to model freezing rain attributes at a finer scale of resolution.

\section{LITERATURE REVIEW}

Freezing rain occurs in an atmosphere in which warm air (i.e. temperatures exceeding $0^{\circ} \mathrm{C}$ ) overruns a shallow dome of subfreezing air at the surface (Stewart 1985). Typically, precipitation begins as snow at higher altitudes and melts as it falls through the warm air. Because the cold air dome is shallow, the resulting rain does not freeze until reaching the surface. The depths of the warm and cold air layers dictate the precipitation type. If the warm air layer is too thin, the snow does not melt completely and a wet snowfall is observed at the surface. On the other hand, a deeper cold air dome at the surface will encourage the freezing of the rainfall before reaching the ground, thus producing sleet (Stewart 1985). In the Appalachian region, freezing rain and other forms of frozen precipitation usually occur when warm moist air from the Gulf of M exico or Atlantic Ocean (see map in Fig. 1) is advected northward over a cold, dry air wedge at the surface. The southerly flow is typically associated with an approaching warm front and low pressure wave from the southwest. The underlying cold air wedge is connected with a surface anticyclone that ridges into the region from the north or northeast and provides a dry northerly to easterly wind flow. This wedge is referred to as a cold air dam (Richwein 1980) because the mountains act as a barrier that focuses cold air advection along and east of the mountains thus allowing the cold air to 'dam up'. During a typical event, the cold air wedge may become more shallow but persists as warm air and moisture advection continue at higher levels. The freezing temperatures are maintained by cold air advection and the adiabatic cooling associated with upslope flow (Forbes et al. 1987). Additionally, evaporative cooling may lead to further temperature decreases (Bell \& Bosart 1988).

Freezing rainfall is extremely difficult to predict because of the narrow range of temperatures associated with its formation. Typically freezing rain lies within a precipitation transition region that includes sleet and/or snow (Stewart 1992). Since the frozen precipitation type depends on the vertical temperature (i.e. thickness) profile of the atmosphere, lower tropospheric thickness is often used to forecast the phenomenon; Keeter \& Cline (1991), for example, developed regression equations to predict freezing precipitation using radiosonde-derived low- and mid-level thickness values as independent variables. Although freezing rain is associated with the occurrence of rainfall in freezing air at the surface, the temperature of the surface ultimately dictates whether or not ice formation occurs. Therefore, various factors including slope aspect and solar insolation on the preceding day can conspire to promote or prevent freezing rain.

The spatial patterns of freezing rain are controlled by topographic features across several scales. On a regional scale, freezing rain and sleet occur with the greatest frequency on the Piedmont and east slopes of the Appalachians (Gay \& Davis 1993), where cold air damming events are common (Bell \& Bosart 1988). Because of the limited number of weather stations that archive freezing rain observations, spatial patterns of freezing rain on finer scales are not known. This is especially the case on Appalachian ridges, where there is a complete absence of weather stations that report hourly observations. At first glance, it would appear that freezing rain occurrence should correlate with elevation. Gay \& Davis (1993) found this to be the case in their study over the southeastern U.S.; however, all of their study sites with 1 exception (i.e. A sheville, NC) are located below $400 \mathrm{~m}$, which is much less than the elevations of most Appalachian ridge tops. Radiosonde data analyzed from several frozen precipitation events (e.g. Keeter et al. 1995) show decreases in temperature with increasing altitude within the cold air wedge. Also, Anthes (1976) examined 2 
precipitation events in which temperature decreases within the cold wedge were associated with a transition from rain in a valley location to freezing rain on an adjacent ridge top. From a climatological perspective, it is unclear if the higher mountain tops typically lie above the cold air wedge in a region where warmer temperatures would inhibit freezing rain. A vertical cross section of temperature developed during a single freezing rain event (see Forbes et al. 1987) depicts a subfreezing cold air wedge that slopes upward with the terrain westward from the Piedmont to the highest Appalachian ridges. This suggests the occurrence of freezing rain over the highest elevations at least during the initial stages of the event. The data used to construct the cross section, however, were limited to several distant soundings and a few surface weather reports in the mountains. Rime icing may conspire with freezing rain to increase the frequency and magnitude of glazing at the highest elevations. Mika et al. (1995), for example, found that icing events in Hungary occurred 5 to 6 times more frequently at a mountainous site where incloud icing events predominated versus a nearby valley site.

\section{STUDY AREA}

The study region for this work lies in the eastern United States and encompasses the southern portion of the Appalachian mountain chain (i.e. Blue Ridge and Val-

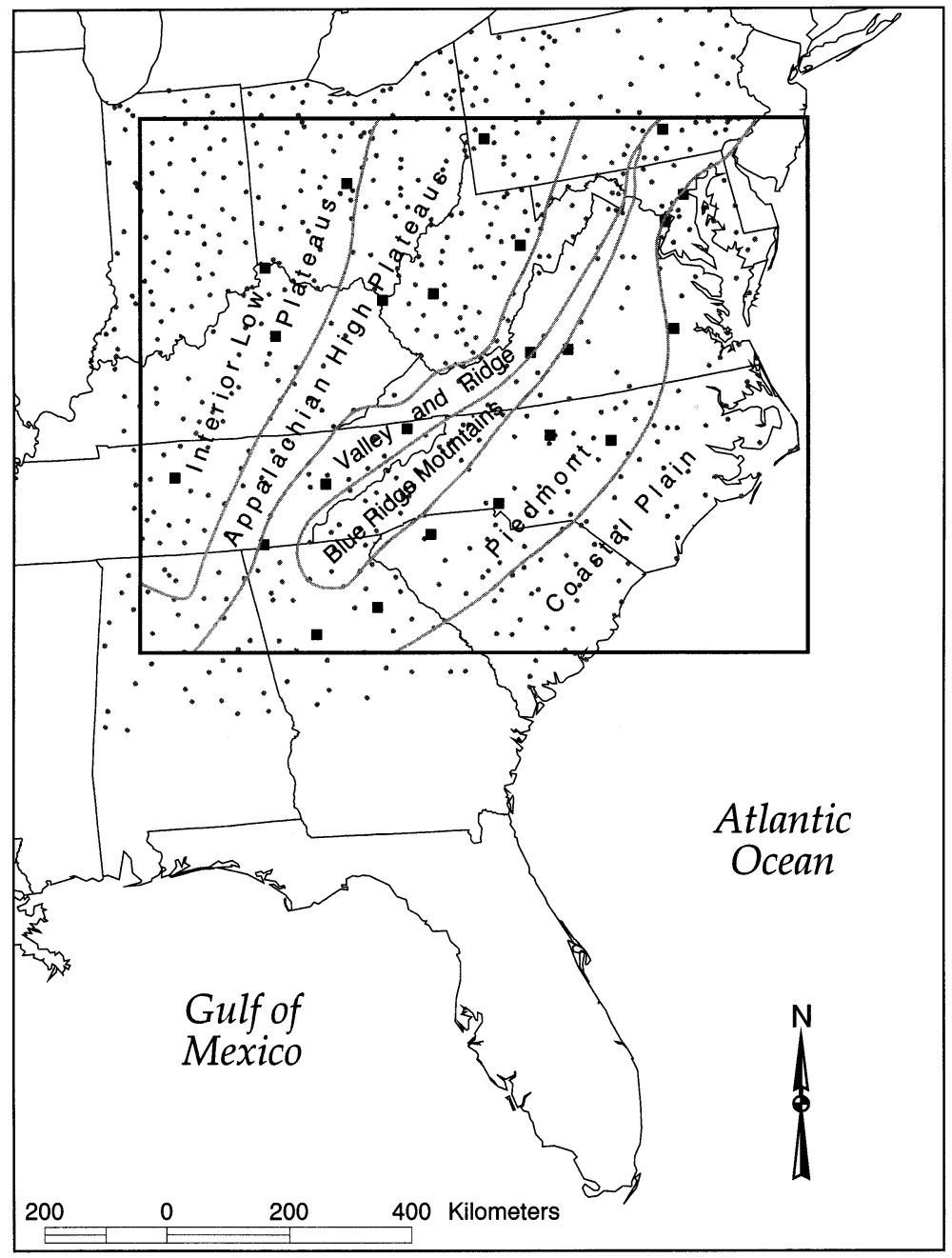

Fig. 1. The study region. Physiographic and state boundaries are denoted by thick and thin lines, respectively. (.) Weather stations in the cooperative observer network that were used to model freezing rain attributes.

(घ) First-order weather stations ley and Ridge physiographic provinces) as well as the upland Piedmont and Plateau regions (Fig. 1). Also included are portions of the Atlantic Coastal Plain and the interior plateau regions which lie to the east and west of the upland area, respectively. M ountain peaks in the Blue Ridge typically range from 1000 to $2000 \mathrm{~m}$ elevation. The Valley and Ridge province is defined by northeast-southwest trending ridges that range in elevation from 600 to $1400 \mathrm{~m}$ and valley bottoms that are generally situated above $300 \mathrm{~m}$ elevation. The Piedmont region, to the southeast of the mountain chain, consists of a gently rolling upland with elevations ranging from $100 \mathrm{~m}$ at the Coastal Plain to over $300 \mathrm{~m}$ at the foot of the Blue Ridge M ountains. The upland areas of the Appalachian Plateau range from $950 \mathrm{~m}$ near the Valley and Ridge province to $300 \mathrm{~m}$ along the northwest boundary.

\section{DATA AND METHODS}

In the study area, hourly observations of weather type were obtained for 23 first-order National Weather Service (NWS) stations within the study region (Fig. 1). These data were downloaded from the NCDC Surface Airways CD-ROM (Earth Info Inc. 1996). For each site, the mean annual number of freezing rain events (NFR) and hours of freezing rain (HFR) were calculated annually for the period 1949 through 1993. At the Greer, SC, site, observations commenced in October 1962 and thus a shorter observation period was used in the calculation of a mean. A freezing rain event was defined by the occurrence of 1 or more hours of freezing rain separated by at least $24 \mathrm{~h}$ from other periods of freezing rain. HFR was defined by the mean annual number of hours of 
Table 1. Correlations between the mean annual number of freezing rain events (NFR) and the mean annual frequencies of daily temperatures within the indicated ranges (on wet days). Correlations exceeding 0.41 are statistically significant at the 0.05 level or higher (for $n=23$ )

\begin{tabular}{|c|c|c|c|c|c|c|}
\hline \multicolumn{7}{|c|}{ Daily maximum temperature $\left({ }^{\circ} \mathrm{C}\right)$} \\
\hline Lower limit & 4.4 & 3.3 & $\begin{array}{c}\text { Uppe } \\
2.2\end{array}$ & $\begin{array}{c}\text { imit - } \\
1.1\end{array}$ & 0.0 & -1.1 \\
\hline 3.3 & 0.40 & & & & & \\
\hline 2.2 & 0.31 & 0.13 & & & & \\
\hline 1.1 & 0.26 & 0.12 & 0.10 & & & \\
\hline 0.0 & 0.26 & 0.15 & 0.15 & 0.18 & & \\
\hline-1.1 & 0.25 & 0.16 & 0.16 & 0.18 & 0.24 & \\
\hline-20.0 & 0.20 & 0.12 & 0.11 & 0.10 & 0.10 & 0.05 \\
\hline \multicolumn{7}{|c|}{ Daily minimum temperature $\left({ }^{\circ} \mathrm{C}\right)$} \\
\hline \multirow[t]{2}{*}{ Lower limit } & & & \multicolumn{2}{|r|}{ imit - } & & \\
\hline & 0.00 & -1.1 & -2.2 & -3.3 & -4.4 & -5.6 \\
\hline-1.1 & 0.83 & & & & & \\
\hline-2.2 & 0.87 & 0.86 & & & & \\
\hline-3.3 & 0.89 & 0.87 & 0.79 & & & \\
\hline-4.4 & 0.89 & 0.85 & 0.76 & 0.65 & & \\
\hline-5.6 & 0.89 & 0.86 & 0.76 & 0.67 & 0.56 & \\
\hline-20.0 & 0.89 & 0.86 & 0.77 & 0.69 & 0.63 & 0.68 \\
\hline
\end{tabular}

measurable freezing rain. In at least 1 other study (Gay \& Davis 1993), observations of freezing drizzle were included in the category of freezing rain. The interest of this study, however, is to identify only those events in which significant icing is observed. Finally, NWS observations were taken every $3 \mathrm{~h}$ during the middle and late 1960s, and thus some events may have escaped detection. This change to $3 \mathrm{~h}$ observations did not significantly affect annual values of NFR and HFR at a firstorder site (i.e. Roanoke, VA) investigated in this study. Daily weather summaries (high and low temperature as well as precipitation and snowfall totals) were obtained from all first-order weather stations and cooperative observer sites from the Cooperative Summary of the Day CD-ROM (NCDC 1995).

The main objective of this work is to search for a variable that integrates the weather summary information (i.e. daily temperature maximum and minimum, precipitation and snowfall totals) on an annual basis in such a way that it correlates strongly with the annual freezing rain attributes at the 23 first-order weather stations. If a strong relationship is identified, this variable can be used to build a regression model that estimates mean annual freezing rain attributes at the cooperative stations that have archived daily weather summaries. Daily weather summary variables investigated in this study included the mean annual number of wet days in which the observed temperature maximum or minimum fell within temperature ranges indicated in Tables $1 \& 2$ (i.e. temperatures near the freez-
Table 2. Correlations between the mean annual number of freezing rain hours (HFR) and the mean annual frequencies of daily temperatures within the indicated ranges (on wet days). Correlations exceeding 0.41 are statistically significant at the 0.05 level or higher (for $n=23$ )

\begin{tabular}{|c|c|c|c|c|c|c|}
\hline \multicolumn{7}{|c|}{ Daily maximum temperature $\left({ }^{\circ} \mathrm{C}\right)$} \\
\hline Lower limit & 4.4 & 3.3 & $\begin{array}{c}\text { Upper } \\
2.2\end{array}$ & $\begin{array}{r}\text { limit } \\
1.1\end{array}$ & 0.0 & -1.1 \\
\hline 3.3 & 0.07 & & & & & \\
\hline 2.2 & -0.03 & -0.20 & & & & \\
\hline 1.1 & -0.09 & -0.22 & -0.23 & & & \\
\hline 0.0 & -0.10 & -0.21 & -0.21 & -0.21 & & \\
\hline-1.1 & -0.11 & -0.20 & -0.20 & -0.20 & -0.15 & \\
\hline-20.0 & -0.15 & -0.23 & -0.23 & -0.24 & -0.23 & -0.27 \\
\hline \multicolumn{7}{|c|}{ Daily minimum temperature $\left({ }^{\circ} \mathrm{C}\right)$} \\
\hline \multirow[t]{2}{*}{ Lower limit } & & & - Uppe & limit & & \\
\hline & 0.00 & -1.1 & -2.2 & -3.3 & -4.4 & -5.6 \\
\hline-1.1 & 0.54 & & & & & \\
\hline-2.2 & 0.65 & 0.71 & & & & \\
\hline-3.3 & 0.71 & 0.77 & 0.83 & & & \\
\hline-4.4 & 0.76 & 0.82 & 0.88 & 0.84 & & \\
\hline-5.6 & 0.79 & 0.85 & 0.91 & 0.90 & 0.84 & \\
\hline-20.0 & 0.79 & 0.85 & 0.91 & 0.89 & 0.84 & 0.67 \\
\hline
\end{tabular}

ing point where freezing rain is common). A day was defined as wet if at least $2.54 \mathrm{~mm}$ of precipitation was observed. Because of the desire to include only significant icing events (i.e. neglect freezing drizzle occurrences), $2.54 \mathrm{~mm}$ of liquid precipitation was arbitrarily assigned as the threshold for significant icing. Since freezing rain is most likely on days in which temperature is near freezing, a set of temperature ranges was targeted along this portion of the temperature spectrum.

Snowfall is often observed in wet situations where the temperature is near freezing; therefore, it is useful to develop a means for not counting wet days in which all of the precipitation falls in the form of snow. To carry this out, the $24 \mathrm{~h}$ snowfall total was converted to a water equivalent (assuming a 10:1 liquid equivalent) and subtracted from the precipitation total. Days with negative precipitation totals indicated a higher likelihood of snowfall than freezing rain and were therefore not considered in the annual statistics (i.e. days with temperatures near freezing and more than $2.54 \mathrm{~mm}$ of precipitation). Obviously numerous events occurred in which a variety of precipitation types were observed, or wet snowfalls (i.e. those with ratios of less than 10:1) occurred that registered as 'positive' precipitation under this assumption. The interest of this study, however, is not to estimate the dominant precipitation type for a particular event, but rather to search for daily weather summary variables that correlate strongly with mean annual freezing rain attributes. 
Correlations between NFR and mean annual frequencies of daily temperature extremes on wet days are provided in Table 1 . Note that the indicated temperature ranges are not mutually exclusive; for example, the frequencies of temperature occurrence between 0 and $-20^{\circ} \mathrm{C}$ include those tabulated in the -1.1 to $-20^{\circ} \mathrm{C}$ range. NFR correlates strongly with most ranges of daily minimum temperature. The highest correlations are found with the mean annual frequencies of daily minimum temperature between 0 and $-20^{\circ} \mathrm{C}$. On the other hand, the mean annual frequencies of daily maximum temperature generally show weak correlations with NFR. HFR also displays stronger relationships with frequencies of daily minimum temperature (Table 2 ). In this case, the strongest correlations are found with frequencies of minimum temperature between -2.2 and $-20^{\circ} \mathrm{C}$.

Using the strongest relationships, the following regression models were constructed:

$$
\begin{aligned}
\mathrm{NFR}= & -0.0201+0.7673 \text { (frequencies of minimum } \\
& \text { temperature between } \left.0.0 \text { and }-20.0^{\circ} \mathrm{C}\right) \\
& \left(\mathrm{R}^{2}=0.801, \mathrm{SE}=0.357\right)
\end{aligned}
$$

$$
\begin{aligned}
\mathrm{HFR}= & -0.6500+10.668(\text { frequencies of minimum } \\
& \text { temperature between } \left.-2.2 \text { and }-20.0^{\circ} \mathrm{C}\right) \\
& \left(\mathrm{R}^{2}=0.830, \mathrm{SE}=2.095\right)
\end{aligned}
$$

The assumptions of linearity in the model and independence between data values were validated through an analysis of the residuals. Fig. 2a, b provides scatter plots of the relationships.

Using the constructed regression models, NFR and HFR were predicted at each cooperative observer weather station in the study area. Only cooperative stations with relatively complete records (i.e. 90\% coverage or greater) were used in the analysis (Fig. 1). There were numerous stations with nearly complete records but for a relatively short time period (i.e. less than $20 \mathrm{yr}$ ). Since the goal of this study is to provide fine-scale details of the spatial pattern of freezing rain, it was tempting to use all of these stations, but given the interdecadal variability in various weather phenomena, it is unclear if the use of these short-term records would produce a biased estimate of the freezing rain attributes. To assess this possibility, mean freezing rain attributes at a first-order weather station were calculated over varying time periods and compared (Table 3). These calculations reveal marked interdecadal variability, and even $20 \mathrm{yr}$ estimates of the freezing rain attributes show some marked departures from the $40 \mathrm{yr}$ estimate (e.g. 13.5 vs $16.7 \mathrm{~h}$ and 2.4 vs 2.7 events). Therefore, it appears that long-term weather records are indeed necessary to gain reasonable estimates of the freezing rain attributes. So only those cooperative stations with
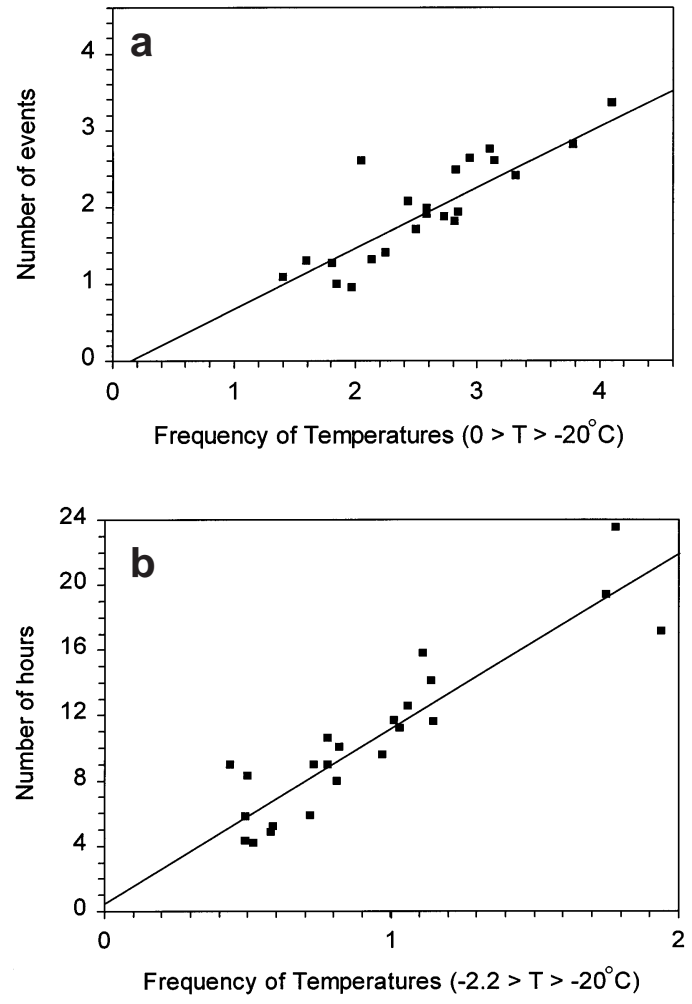

Fig. 2. Scatter plots of the annual number of (a) freezing rain events (NFR) and (b) freezing rain hours (HFR) versus the annual frequencies of daily minimum temperature between 0.0 and $-20.0^{\circ} \mathrm{C}$, and between -2.2 and $-20.0^{\circ} \mathrm{C}$, respectively, on wet days

relatively complete records of $30 \mathrm{yr}$ or more were used in the analysis.

In order to run the model, the dependent variables (i.e. mean annual frequencies of minimum temperatures during wet days) were first calculated at each site. In estimating these variables, short-term time gaps in the record (i.e. missing data) may exert an influence; therefore, the length of these recording gaps was deducted from the station record length (i.e. ending date - beginning date) before calculating the dependent variable.

Table 3. Comparisons of NFR and HFR at Roanoke, VA, for various time periods

\begin{tabular}{|lccc|}
\hline Period & Number of years & NFR & HFR \\
\hline $1954-1993$ & 40 & 2.7 & 16.7 \\
$1954-1973$ & 20 & 3.1 & 17.9 \\
$1974-1993$ & 20 & 2.4 & 13.5 \\
$1954-1963$ & 10 & 3.5 & 21.0 \\
$1964-1973$ & 10 & 2.6 & 14.8 \\
$1974-1983$ & 10 & 3.0 & 16.5 \\
$1984-1993$ & 10 & 1.8 & 10.5 \\
\hline
\end{tabular}




\section{RESULTS}

Before presenting maps of the modeled attributes of freezing rain, it is useful to show the broad-scale patterns as revealed from the observed freezing rain observations at the 23 first-order weather stations. NFR ranges from nearly 4 events $\mathrm{yr}^{-1}$ in southern Pennsylvania to 1 event $\mathrm{yr}^{-1}$ in northeast A labama and southeastern Tennessee (Fig. 3a). Over the broadest scales, NFR increases with latitude, but superimposed on this pattern is a region of high NFR in the Piedmont and Blue Ridge Mountains and low NFR on the Appalachian high plateau. As mentioned earlier, the former region is subject to frequent occurrences of cold air damming during precipitation episodes. On the Appalachian high plateau and westward, large-scale precipitation events are often accompanied by low-level winds that advect warm air northward. The NFR minimum, however, is confined to the plateau region immediately west of the highest ridges. In this region, freezing rain may be further inhibited due to the occurrence of adiabatic warming associated with downsloping southerly or easterly winds. It should be noted that these wind trajectories are common to the east of approaching cyclonic disturbances that typically bring frozen precipitation to the eastern U.S.

A similar spatial pattern of HFR is noted over the Appalachian region (Fig. 4a), but there are 2 differences. First, the increase in HFR with increasing latitude over the broadest scales is not so marked; in fact, the HFR maximum for the region is not even found over the northern portions of the study region. Second, the increase in HFR over the Piedmont and Blue Ridge regions is especially marked when contrasted with the HFR minimum found on the west side of the mountain chain. In particular, HFR is more than $300 \%$ greater on the east side of the mountains; this is in contrast to a $175 \%$ increase in NFR observed across the same region.

The maps of modeled NFR which were drafted from the modeled estimates only reveal much more regional detail and complexity in the spatial patterns of freezing rain (Fig. 3b). Similar broad-scale patterns are noted in comparing the observed and modeled patterns, but there is much more variability in the modeled values of NFR especially in the immediate vicinity of mountains and plateaus. The highest values of NFR are found along the northern fringes of the study area (e.g. west central Pennsylvania) on an elevated plateau region. Other areas of higher elevation show locally increased values of NFR as well (e.g. Blue Ridge M ountains and locally higher portions of the Appalachian high plateau in West Virginia and Tennessee). Unfortunately, the vast majority of the cooperative observer stations are situated in valley bottoms as opposed to the mountain ridges; therefore, maps of freezing rain occurrence will neglect local maxima on these ridges. In portions of the Blue Ridge M ountains, NFR and HFR were calculated at a few high elevation sites with less complete records (i.e. less than $90 \%$ coverage) to gain a rough estimate of the increase in freezing rain occurrence. These estimates were used to better delineate freezing rain patterns in the vicinity of the Blue Ridge M ountains. The lowest values of NFR are found on the coastal plain; additionally, low values are identified in some of the valleys that dissect the high plateau (e.g. western West Virginia), where adiabatic warming apparently exerts some influence.

The spatial patterns of modeled HFR also reveal greater regional-scale variability (Fig. 4b), but there are some subtle differences in the broad-scale pattern. First, the modeled HFR values are slightly higher than the observed values immediately west of the Appalachian mountain crest. In portions of this region, the cooperative observer sites which were used to model the freezing rain are situated at higher elevations relative to the nearest first-order weather stations and thus one would expect higher modeled values. Second, the maximum in the modeled HFR is found in south central Pennsylvania instead of central Virginia. Since there are no stations in west central Pennsylvania that report freezing rain, it is conceivable that freezing rain does indeed occur more frequently in this region than elsewhere. Also, much of this region is elevated and thus one would expect more freezing rain. Modeled values of HFR appear to correlate with elevation over the western three-quarters of the mountains. Along the eastern slopes, however, HFR values in the higher elevations of the mountains ( $800 \mathrm{~m}$ and greater) are comparable to those in the Piedmont (100 to $300 \mathrm{~m}$ ), where cold air damming is most common.

In order to provide the estimates of the spatial patterns of freezing rain, the maps developed from the first-order stations (Figs. 3a \& 4a) and the modeled values from the dense network of cooperative stations (Figs. 3b \& 4b) were blended (Figs. 3c \& 4c). The blended maps were drafted to match the observed data at the first-order weather sites (i.e. ground truth), and the cooperative station data was used to add mesoscale details to this map.

\section{DISC USSION AND CONCLUSIONS}

In this study, the mean annual number (NFR) and hours (HFR) of freezing rain events were modeled over a dense network of cooperative observer sites in the Appalachian region. To develop the model, mean annual frequencies of daily high and low temperature on wet days were correlated with the freezing rain 

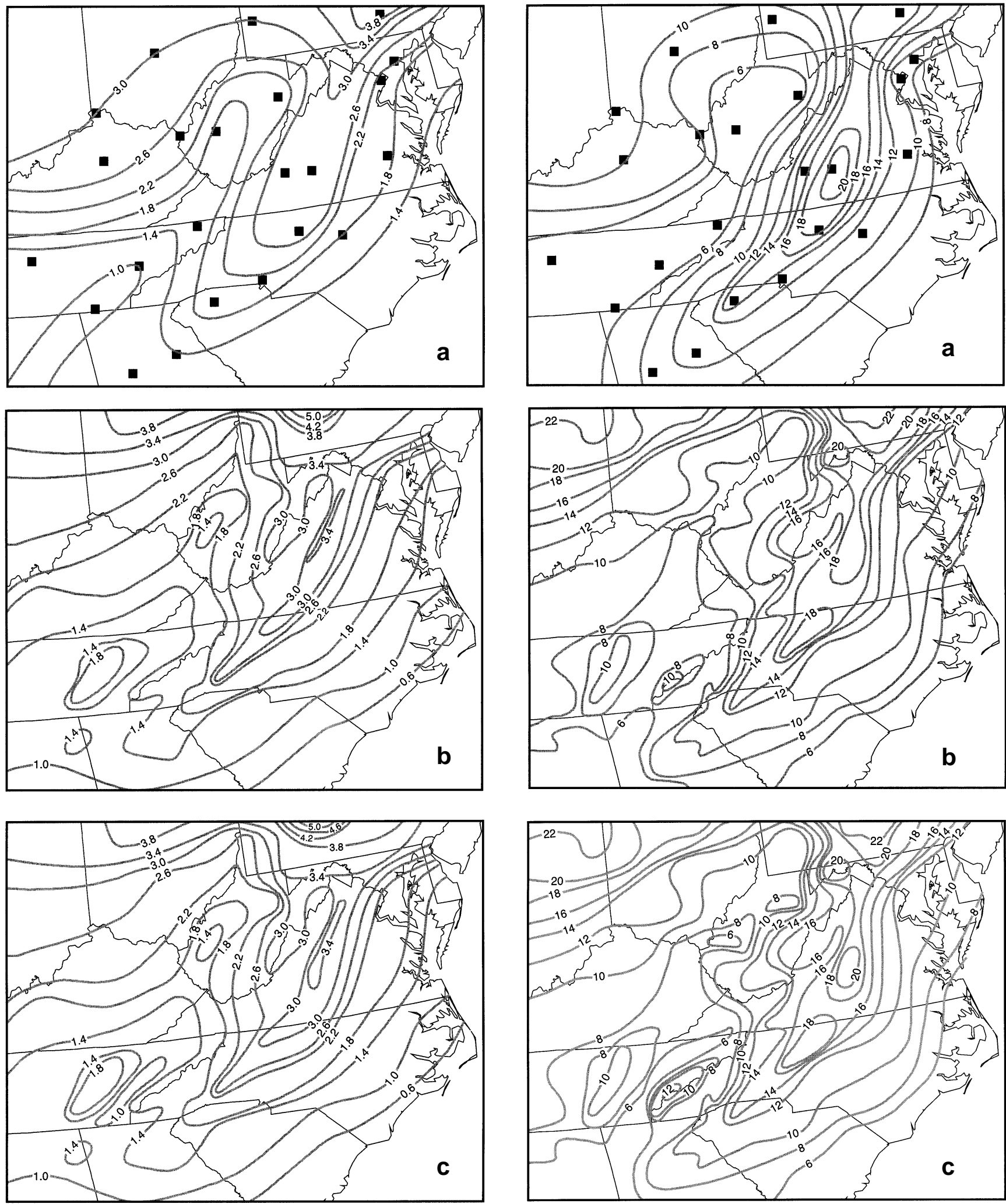

Fig. 3. Pattern of NFR from (a) first-order weather stations ( $\mathbf{\square})$ that report hourly weather types, (b) regression model estimates at the cooperative observer sites, and (c) a blending of observations from first-order weather stations and regression model estimates at the cooperative observer sites

Fig. 4. Pattern of HFR from (a) first-order weather stations ( $\boldsymbol{\square}$ ) that report hourly weather types, (b) regression model estimates at the cooperative observer sites, and (c) a blending of observations from first-order weather stations and regression model estimates at the cooperative observer sites 
attributes at 23 first-order weather sites that provide hourly reports of precipitation type. Using the strongest correlations as a guide, regression models were constructed to predict NFR and HFR using mean annual frequencies of daily temperature (within a particular range) on wet days as an independent variable. Both models explained over $80 \%$ of the variance in the dependent variable (i.e. NFR and HFR). The models were applied to climatological summaries of daily weather over a dense network of cooperative observer sites to predict finer-scale spatial patterns of freezing rain in the study area.
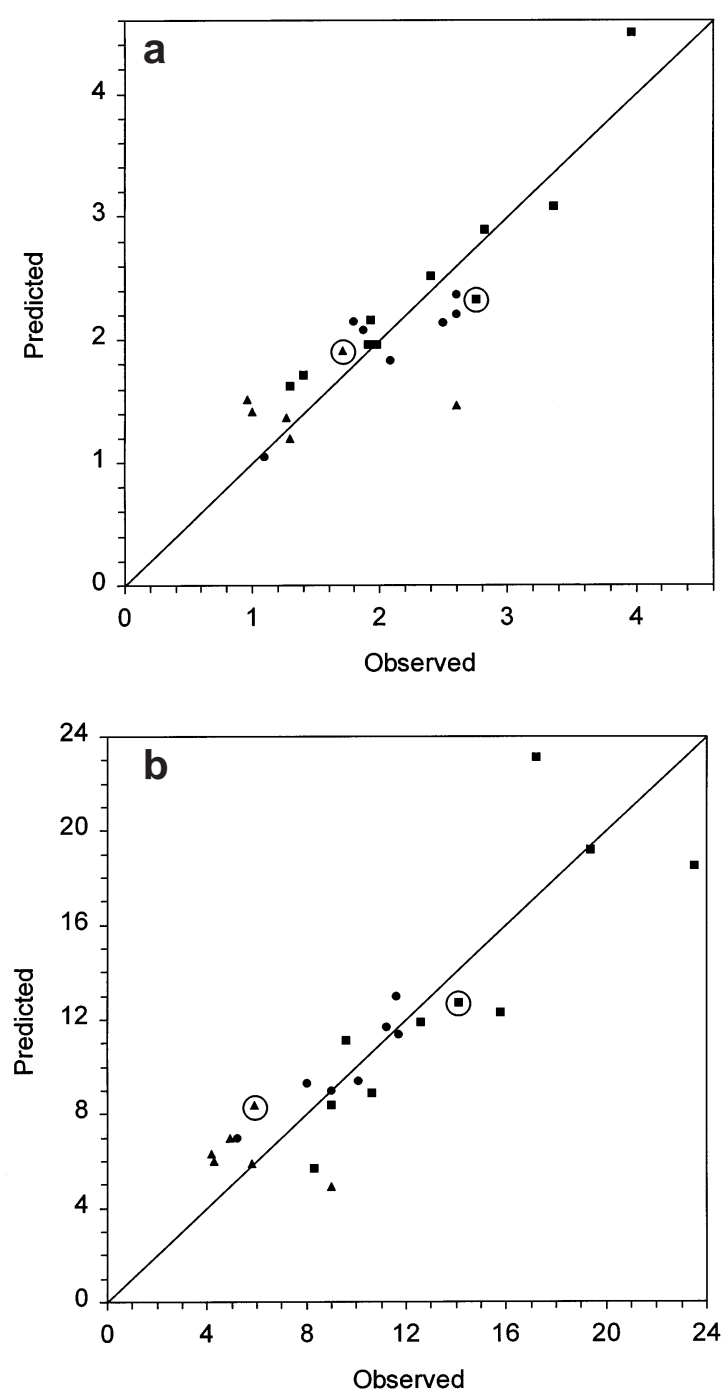

Fig. 5. Predicted versus observed values of (a) NFR and (b) HFR as obtained from a cross-validation analysis at the 23 first-order weather stations. $(\mathbf{\square}, \mathbf{\Delta})$ Stations located within $100 \mathrm{~km}$ of the southeastern and northwestern sides of the mountain chain, respectively. (๑) Stations that are more than $100 \mathrm{~km}$ from the mountain chain. Roanoke, VA, and Elkins, WV, which are situated within $10 \mathrm{~km}$ of mountains exceeding $300 \mathrm{~m}$, are highlighted with large open circles
Although the relationships developed in this work between freezing rain and mean annual temperature frequencies are strong, it is not clear whether they are stable across the study domain. This is especially pertinent in mountainous areas, where local circulations potentially influence precipitation type. For example, adiabatic cooling due to orographic lifting over finescale terrain features can potentially deepen the surface layer of cold air to the point that sleet develops at the expense of freezing rain. From a synoptic climatological perspective, however, the form of the frozen precipitation may not be consistent from one event to the next. For example, uplift may encourage sleet instead of freezing rain in some events, but with a more shallow freezing layer, freezing rain may be favored over rain. Other aspects of orographic uplifting can impact precipitation type as well. Stable atmospheric conditions can promote a 'backing up' of the upslope flow and development of a low-level layer of air that is decoupled from the large-scale circulation (Smith 1979). This in turn fosters a broader-scale uplift above the decoupled layer that is unresponsive to smaller-scale terrain features. In this case, local differences in precipitation type would be dictated by elevation (e.g. rain at lower elevations and freezing rain or snow above the freezing level) and not by the terraininduced upslope on the local scale.

To identify whether the relationships identified between freezing rain and annual frequencies of minimum temperature change across the study region (i.e. exhibit spatial dependence), a cross-validation analysis was carried out. The observed attributes of freezing rain at each of the 23 first-order weather stations were compared with attributes predicted from a regression model constructed using the remaining 22 stations. By using this approach, an independent means is provided for assessing the validity of the regional-scale regression model at each station. As shown in Fig. 5, the errors (i.e. the predicted minus observed values) are relatively low at most locations. There is a slight regional pattern in the HFR, however, as most sites on the southeastern side of the Appalachians display slightly positive values. One notable exception is Harrisburg, PA, which has the highest predicted values of freezing rain hours.

If local, terrain-driven circulations influence the relationships developed in this study, relatively larger errors should result between the observed and model predicted values at sites located nearer to mountainous relief. This is not case, however, at the 2 most mountainous first-order stations (i.e. Roanoke, VA, and Elkins, WV) in the study, for which the errors are less than those at various sites situated away from the mountains (Fig. 5). Obviously a larger sample of stations is necessary to prove unequivocally that terrain- 
induced circulations do not affect the climatological relationships derived in this work. Also, a more rigorous validation of the model would require long-term weather data from stations situated on ridge tops.

Another potential source of error in the model involves the stipulation of significant precipitation (at least $2.54 \mathrm{~mm}$ ) in identifying the annual number of days in which the temperature is in a given range. Precipitation amounts generally increase with elevation, especially on the windward slopes (Barros \& Lettenmaier 1994, Konrad 1996). Since the stations used to develop the model are situated in valleys or plains, the model may underestimate values of the independent variable on the windward slopes, where more days of significant precipitation are observed relative to the valley sites.

Although the cross-validation analysis provided a means for assessing the accuracy of the regressionbased technique, the validity of the freezing rain maps developed from the technique has not been assessed; in particular, it is not clear that the modeled values provide better estimates than those obtained by simply extrapolating from the first-order weather stations where the freezing rain attributes are known. Ideally, the best method of validating the results is to identify an independent set of stations and compare the observed values with the predicted and extrapolated values. As shown in the methodology section, the records from these stations must be long-term (i.e. at least $20 \mathrm{yr}$ ) and nearly complete. A search for independent freezing rain data turned up only 2 stations with long-term records. With only 2 stations available for validation, no definitive conclusions can be made regarding the accuracy of the detailed map. As shown in Table 4, the predicted values of NFR are indeed better than the extrapolated values at both sites, especially Beckley, WV. Also, in the case of HFR, the predicted value is markedly closer to the observed value at Beckley. However, this is not the case at Asheville, where the extrapolated value of HFR nearly matches the observed value.

Several caveats deserve mention in the interpretation of the freezing rain maps. First, the spatial variability of the freezing rain pattern is a function of the density of the cooperative stations in which freezing rain estimates are developed. Variability on finer scales simply cannot be discerned. Since most of the cooperative weather stations are situated in the valleys, the maps do not depict the elevated freezing rain attributes on the mountain top and the local-scale variability that results from the terrain. Second, local patterns of freezing rain occurrence are mediated by microclimate; therefore, NFR and HFR may be underestimated (overestimated) on hilltops, north-facing, windward slopes, and shaded areas (south-facing
Table 4. Comparisons between observed, predicted, and extrapolated freezing rain attributes (NFR and HFR) at 2 weather sites not used in the study

\begin{tabular}{|lrrrr|}
\hline & \multicolumn{3}{c}{ Asheville, NC } & \multicolumn{3}{c|}{$\begin{array}{c}\text { Beckley, WV (1963-1993) } \\
\text { NFR }\end{array}$} & HFR & NFR & HFR \\
\hline Observed & 2.20 & 10.2 & 3.8 & 15.9 \\
Predicted & 1.77 & 7.8 & 2.2 & 12.5 \\
Extrapolated & 1.70 & 10.1 & 1.7 & 6.5 \\
\hline
\end{tabular}

Table 5. Correlations between the freezing rain attributes (NFR and HFR) and elevation for selected cooperative observer sites in the indicated regions. Correlations exceeding 0.490 are statistically significant at the 0.05 level or higher

\begin{tabular}{|lccc|}
\hline Region & $n$ & NFR & HFR \\
\hline Blue Ridge of western N orth Carolina & 16 & 0.847 & 0.898 \\
Western A ppalachians of West Virginia & 16 & 0.458 & 0.438 \\
\hline
\end{tabular}

slopes and open and urban areas). Third, the freezing rain attributes may not correlate highly with ice buildup on the higher peaks of the Appalachians where rime icing occurs.

Freezing rain attributes generally display a positive relationship with elevation. If the relationship is strong, regression modeling may be used to predict the phenomenon on ridges where cooperative stations are sparse. In the study region, no high elevation weather stations are known to record freezing rain; however, the regression models developed in this study can predict freezing rain attributes at some high elevation cooperative observer sites. To see if the freezing rain attributes relate to elevation, correlation coefficients were calculated and scatter plots were constructed for a sample of sites in 2 mountainous regions in the study area (Table 5 and Fig. 6, respectively). In the Blue Ridge of North Carolina, a strong relationship was identified between freezing rain and elevation, but in the western Appalachians of West Virginia the relationship was weaker and not statistically significant. Along the east slopes of the Blue Ridge, the freezing rain attributes do not correlate with elevation; in fact, some Piedmont sites where cold air wedges are especially persistent display higher frequencies of freezing rain than locations in the Blue Ridge M ountains. These results suggest that the strength of the correlation between freezing rain and elevation varies markedly across the study region.

Previous work on cold air damming and freezing rain leaves open the question of whether or not a threshold elevation exists above which freezing rain occurrence decreases with increasing elevation (i.e. highest peaks exposed to warm air advection above the cold air 

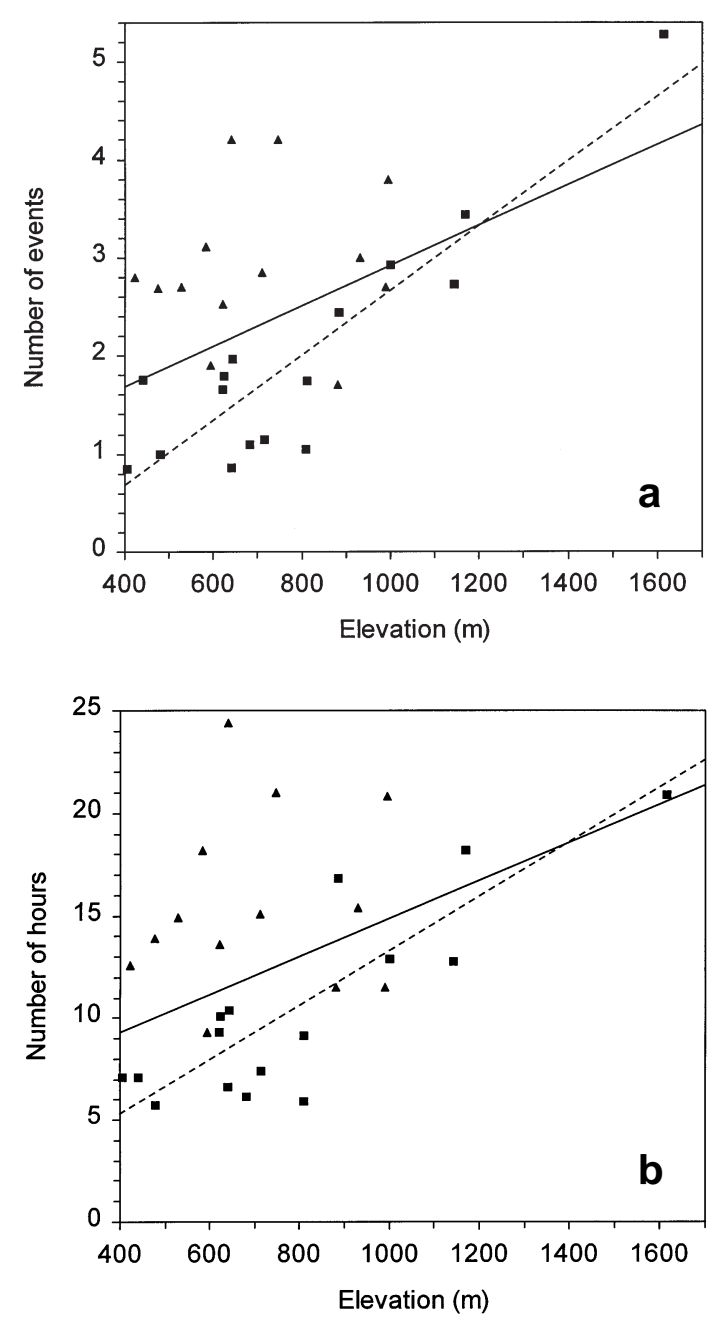

Fig. 6. Scatter plot of (a) NFR and (b) HFR estimates at selected cooperative observer sites in the Blue Ridge Mountains of western North Carolina ( $\mathbf{\square}$ and dashed line) and the western Appalachian region of West Virginia ( $\mathbf{\Delta}$ ) versus elevation. The best-fit regression line for both samples of sites is indicated by a solid line

wedge). The results of this work suggest that no such threshold exists as the highest elevation sites in the study area (e.g. Grandfather M ountain in North Carolina at $1615 \mathrm{~m}$ ) yield the highest values of NFR and HFR. Apparently the cold air wedge during many freezing rain events slopes upward over the highest peaks, perhaps in response to the adiabatic cooling of the upslope flow.

In conclusion, the empirical technique developed in this work provides a viable alternative to the simple interpolation of freezing rain attributes from a coarse network of low-elevation stations. By exploiting information from daily climatological summaries that correlates with the occurrence of freezing rain, the technique provides output for more detailed maps of the phenomenon, especially in areas of mountainous terrain. The accuracy of the freezing rain estimations relative to various extrapolation techniques, however, needs to be tested using a larger sample of stations. With the growth of weather reporting networks, such as those used by highway departments and utility companies, more information regarding the occurrence of freezing rain is becoming available. Future work might be aimed at analyzing this data in case study analyses of freezing rain events. From these analyses, relationships can be developed between frozen precipitation occurrence and fine-scaled topographic features. The major challenge will be to translate these relationships, which are derived from a small sample of events, into climatological ones that reveal the fine-scaled patterns of freezing rain over complex terrain.

Acknowledgements. The author thanks Tracy Steen for her assistance with the organization of the cooperative observer network data and Becky Dobbs for her cartographic work. I thank Robert Davis, Dan Leathers, and 1 anonymous reviewer for their thorough and insightful comments.

\section{LITERATURE CITED}

Anthes RA (1976) Variations in temperatures and freezing conditions between mountaintops and valleys in Central Pennsylvania. Weatherwise 29:178-183

Barros AP, Lettenmaier DP (1994) Dynamic modeling of orographically induced precipitation. Rev Geophys 32: 265-284

Bell GD, Bosart LF (1988) Appalachian cold-air damming. Mon Wea Rev 116:137-161

Earth Info Inc (1996) NCDC surface airways CD-ROM. Earth Info Inc, Boulder, CO

Forbes GS, Anthes RA, Thompson DW (1987) Synoptic and mesoscale aspects of an Appalachian ice storm associated with cold-air damming. M on Wea Rev 115:564-591

Gay DA, Davis RE (1993) Freezing rain and sleet climatology of the southeastern USA. Clim Res 3:209-220

Keeter KK, Cline J W (1991) The objective use of observed and forecast thickness values to predict precipitation type in North Carolina. Wea Forecast 6:456-469

Keeter KK, Businger S, Lee LG, Waldstreicher J S (1995) Winter weather forecasting throughout the eastern United States. Part III: The effects of topography and the variability of winter weather in the Carolinas and Virginia. Wea Forecast 10:42-60

Konrad CE (1996) Relationships between precipitation event types and topography in the southern Blue Ridge Mountains of the southeastern USA. Int J Climatol 16:49-62

Mika J, Szentimrey T, Csomor M, Kover Z, Nemes C, Domonkos P (1995) Correlation of ice load with largescale and local meteorological conditions in Hungary. Atmos Res 36:261-276

NCDC (National Climate Data Center) (1994) Weather in the southeast: February ice storm and July flooding. TR 94-03, US Department of Commerce, National Oceanic and Atmospheric Administration (NOAA), Asheville, NC

NCDC (National Climate Data Center) (1995) Cooperative summary of the day CD-ROM. US Department of Com- 
merce, National Oceanic and Atmospheric Administration (NOAA), Asheville, NC

NCDC (National Climate Data Center) (1998) Eastern US flooding and ice storm. TR 98-01, US Department of Commerce, National Oceanic and Atmospheric Administration (NOAA), Asheville, NC

Richwein BA (1980) The damming effect of the southern Appalachians. Natl Wea Dig 5:2-12

Smith RB (1979) The influence of mountains on the atmos-

Editorial responsibility: Brent Yarnal,

University Park, Pennsylvania, USA phere. Adv Geophys 21:87-230

Stewart RE (1985) Precipitation types in winter storms. Pure A ppl Geophys 123:597-609

Stewart RE (1992) Precipitation types in the transition region of winter storms. Bull Am M eteorol Soc 73:287-296

Travis DJ, Meentemeyer V (1991) Influence of glaze ice storms on growth rates of loblolly pine Pinus taeda and shortleaf pine Pinus echinata in the southern Appalachian Piedmont. Clim Res 1:199-205

Submitted: December 12, 1997; Accepted: September 18, 1998 Proofs received from author(s): December 7, 1998 